\title{
Justification for Inclusion of Domestic Enzymes in Feed of Laying Hens
}

\author{
A Yu Lavrentiev*, VS Sherne and NV Danilova \\ Chuvash State Agricultural Academy, University in Cheboksary, Russia
}

*Corresponding author: A Yu Lavrentiev, Federal State Budgetary Educational Institution of Higher Education Chuvash State Agricultural Academy, University in Cheboksary, Cheboksary, Russia.

To Cite This Article: A Yu Lavrentiev. Justification for Inclusion of Domestic Enzymes in Feed of Laying Hens. Am J Biomed Sci \& Res. 2019 - 4(4). AJBSR.MS.ID.000807. DOI: 10.34297/AJBSR.2019.04.000807

Received: July 23, 2019 | Published: August 06, 2019

\begin{abstract}
Great demands are raised to feed poultry concerning their composition, as they contain several types of grain feed, which contain anti-nutrients that reduce the digestibility and use of these nutrients. Low nutritional value of several grains is since there are significant amounts of other nonstarchy polysaccharides, which include beta-glucans and pentosansalong with fiber in them. According to generalized data, the main anti-nutritional factors and wheat, rye and triticale are pentosans, most of which are arabinoxylans. Beta glucans mainly have a negative impact on the absorption of nutrients in barley. Non-starchy polysaccharides have another negative property-they strongly swell, forming viscous adhesive solutions that limit the absorption of already digested protein, starch, fat, and other important biological compounds. The use of enzyme preparations in feed inactivates anti-nutrients, promotes better digestion and use of feed nutrients. This helps to increase egg production and improve the quality of eggs.

Keywords: Laying Hens, Enzymes, Feed, Egg Production, Egg Mass, Egg Quality, Feed Consumption
\end{abstract}

\section{Introduction}

One of the most important tasks of the domestic poultry industry is to reduce losses by increasing the digestibility of feed and the use of digested nutrients in a better way. Among the most effective ways to solve this problem is the addition of exogenous enzymes to feed before feeding it to poultry. Unlike hormones and bio stimulants, enzymes do not act on the body of animals, but on the components of food in the gastrointestinal tract, they do not accumulate in the body and poultry and livestock products. While splitting or synthesizing substances, the enzymes themselves may not change. They are not included in the final products of the reaction, are not consumed during their process and remain in the same amount after the complication. The inclusion of enzyme preparations in the compound feeds contributes to the inactivation of these anti-nutrients, which increases the coefficient of digestibility of nutrients $[1,2]$.

Competitiveness of an agricultural enterprise in the Russian market directly depends on the use of modern technologies of feeding and the maintenance of agricultural birds, purchase of genetically full herd, advanced training of personnel. The key factor is the quality of the feed, as it is the main part of the costs in production, which affects the productive performance of poultry. This necessarily requires a balance of feed complex nutrients and biologically active substances [3-5].
The most important problem for producers is to increase the productivity of poultry and at the same time reduce the cost of final products. The problem of reducing feed costs for egg products is becoming more acute every year. We must not forget that the bird is a competitor of man in the consumption of cereals and legumes, besides the prices of these types of feed raw materials are growing every year, and the share of feed in the cost of eggs is not reduced and is $65-70 \%$. The urgency of the problem increases due to the transition of many poultry farms to their own production of animal feed. It is important to have objective information not only about the nutritional value but also the anti-nutritional factors of raw materials of own production used for the manufacture of compound feed. In poultry farming, barley, oats, rye, non-food wheat and products of their processing are used as the main concentrated feed [6-8].

According to generalized data, the main anti-nutritional factors of wheat, rye, and triticale are pentosans, most of which are arabinoxylans. Beta glucans mainly have a negative impact on the absorption of nutrients in barley. Non-starchy polysaccharides have another negative property-they strongly swell, forming viscous adhesive solutions that limit the absorption of already digested protein, starch, fat, and other important biological compounds. One of the most important tasks of the domestic poultry industry is to 
reduce losses by increasing the digestibility of feed and the use of digested nutrients in a better way. Among the most effective ways to solve this problem is the addition of exogenous enzymes to feed before feeding it to poultry $[9,10]$.

Ferments (a synonym for enzymes) are specific proteins that act as biological catalysts in a living organism. While splitting or synthesizing substances, the enzymes themselves may not change. They are not included in the final products of the reaction, are not consumed during their process and remain in the same amount after the complication $[10,11]$. The purpose of this work is to establish the feasibility and effectiveness of enrichment of feed used in the technology of production of chicken eggs mixtures of enzyme preparations of domestic production of amylosubtiline G3x, celloluxe-F, and protosubtiline G3x [11,12].

\section{The Objects and Methods of Research}

To conduct the experiment, three groups of laying hens were formed, 57 heads in each: one control and two experimental groups. The experiment consisted of two periods: the preparatory period with a duration of 21 days and a basic duration of 420 days. The age of laying hens during the preparatory period of the experiment was 18 weeks, the beginning of the main period at the age of 22 weeks, and at the end of the experiment for 81 weeks. Laying hens of the first experimental group received feed control group PC 1-1, enriched with enzyme preparations, depending on age: 22-33 weeks - amylosubtilin G3x in the amount of $100 \mathrm{~g}$ and cellulose - F $50 \mathrm{~g}$ per 1 ton of feed. At the age of 34-53 weeks, the hens received feed PC 1-2, enriched with enzyme preparations-amylosubtilin G3x in the amount of $150 \mathrm{~g}$ and cellolux $-\mathrm{F} 75 \mathrm{~g}$ per 1 ton of feed. At the age of 54-81 weeks, the hens received PC 1-3, enriched with enzyme preparations-amylosubtilin G3x in an amount of $200 \mathrm{~g}$ and cellolux-F 100 g per 1 ton of feed. Enzyme preparations were additionally introduced into the feed of laying hens of the second experimental group depending on the age: 22-33 week in PC-1-2amilosubtilin $50 \mathrm{~g} \mathrm{G} 3 \mathrm{x}$ and G3x protosubtilin $50 \mathrm{~g}$ per 1 ton of feed, 34-53 week in PC-1-3- amilosubtilin $75 \mathrm{~g}$ G3x and G3x protosubtilin $75 \mathrm{~g}$ per 1 ton of feed, 54-81 week in PC-1-3 -amilosubtilin $100 \mathrm{~g}$ G3x and G3x protosubtilin $100 \mathrm{~g}$ per 1 ton of feed.

Amylosubtiline G3x contains in its composition enzymes (alpha-amylase, neutral and slightly alkaline proteinases, beta-glucanase, cellulase, xylanase), the remains of the nutrient medium chalk, table salt, corn flour. It is produced with amylolytic enzyme activity of $600 \mathrm{u} / \mathrm{g}$ to 1,500 units/g. The pharmacological effect of amylosubtilin G3x, added to feed, is to increase their digestibility. The General effect of amylosubtilin G3x is associated with the combined effect of all enzymes included in the preparation, including beta-glucanase, xylanase, and cellulase, catalyzing the cleavage of hard-to-digest barley, wheat and rye polysaccharides, hydrolysis of which gives an additional amount of sugars.
The main area of application of celloluxe- $F$ is the use in poultry to improve the nutritional value of feeds. CelloLux-F contains cellulase complexes $(2000 \pm 200 \mathrm{u} / \mathrm{g})$, xylanase up to $8000 \mathrm{u} / \mathrm{g}$, glucanase up to $1500 \mathrm{u} / \mathrm{g}$. Catalyzes the breakdown of cellulose, xylans, betta-glucans of plant cells to readily available sugars. The positive effect of the action of the enzyme complex cellolux-F is manifested in an increase in the content of glycogen, lipids, protein and free amino acids in the body of the animal, especially in young animals during intensive growth. Protosubtiline G3x is used as a feed additive in diets to improve the availability of protein components of feed by the body of poultry, primarily of plant origin. Promotes the destruction of plant cell membranes and improves digestibility and nutrient absorption of feed. Splitting high-molecular proteins increase the content of available peptides and amino acids in the feed.

\section{Research Result}

During the scientific and economic experience, feeding of laying hens of all groups was carried out by dry complete feed. The control and experimental group of laying hens received feed mixture corresponding to that period of the PC 1-1 (age of laying hens 22-40 weeks), $100 \mathrm{~g}$. of which contained $263 \mathrm{kcal}$ of metabolizable energy, crude protein-16.48\%, Calcium 3.44 percent and the phosphorus to $0.78 \%$. At the age of $41-60$ weeks, feed PK-1-2 was obtained, in $100 \mathrm{~g}$ of which $252 \mathrm{kcal}$ of metabolic energy, crude protein $-16.1 \%$, Calcium $3.82 \%$, and phosphorus $0.48 \%$. At the age of 61 weeks and older, experimental laying hens received feed PK-1-3, $100 \mathrm{~g}$ of which $249 \mathrm{kcal}$ of metabolic energy and crude protein - 15\%, Calcium $4.14 \%$, and phosphorus $0.39 \%$.

The main part of the feed is cereals (barley, wheat) with a specific weight of $63.39 \%$. Meat and bone meal of $6 \%$ and sunflower meal in the amount of $15 \%$ were used as sources of high-grade protein. DL-methionine in an amount of $0.01 \%$ is introduced to improve the amino acid composition of methionine. As a source of minerals shell flour, limestone, tricalcium phosphate, salt was used. To increase the energy value of feed sunflower oil was introduced in the amount of $3 \%$. BVMC - $5 \%$, met+cis5.5 -5\% was introduced for the enrichment of protein, vitamins, and minerals in the diet. The composition and nutritional value of compound feed corresponded to the requirements for feeding laying hens depending on age and egg production.

Recommended parameters of feed nutrition depending on the phase of chicken productivity should be connected to the daily rate of feed per 1 head. With this purpose, an audit of the given feeds and their residues was conducted every ten days. It showed that laying hens at the age of 22-40 weeks had the highest feed intake per day in the control group - $116 \mathrm{~g}$, and the lowest - in the first experimental group (received amylosubtilin G3x and cellolux-F)-113 g, the second experimental group (received amylosubtilin G3x and protosubtilin G3x) ate $114 \mathrm{~g}$ per head per day. The difference in feed intake between the control and the first experimental group 
was only $3 \mathrm{~g}$ or $2.5 \%$, between the control and the second experimental $2 \mathrm{~g}$ or $1.1 \%$. The same trend continued was observed by the end of the experiment. At the age of 61 weeks and older, the difference in feed intake between the control and the first experimental group was $8 \mathrm{~g}$ or $7.8 \%$, and between the control and the second experimental group $4 \mathrm{~g}$ or $3.2 \%$.

The analysis and quantity of the eaten compound feed showed that feeding of laying hens of control and experimental groups corresponded to the detailed norms of feeding on age and egg-laying. Egg productivity of laying hens. The dynamics of egg productivity of laying hens of experimental groups, considering the age, showed that this indicator changes during oviposition. Egg laying capacity of hens of the experimental groups was higher than from laying hens of the control group. Laying hens of the first experimental group showed the greatest egg productivity, their egg production for 60 weeks (420 days) was 357.81 eggs from one laying hen for the main period, which is 23.22 pieces or $6.48 \%$ higher than in the control group (334.59 pieces) and 6.91 pieces or $1.84 \%$ more (350.9 pieces) than in the 2 experimental group. The indicator of egg productivity of laying hens of the second experimental group was higher than the corresponding indicator in the control group by 16.31 or $4.64 \%$. The highest value of egg production for the experimental period was found in laying hens of all groups at the age of 30-37 weeks.

Weight of eggs. In order to establish the effect of fed enzyme preparations on egg weight, all eggs received from each group of chickens were weighed last five days at the end of each month of oviposition. The data obtained showed a favorable effect of the mixture of enzyme preparations on egg weight. Thus, in the control group, the average egg weight for the period of oviposition was $62.37 \mathrm{~g}$, and in the $1 \mathrm{st}$ experimental group- $64.22 \mathrm{~g}$ or $1.85 \mathrm{~g}$ more than in the control group, in the 2nd experimental group-63.07 g or $0.7 \mathrm{~g}$ more than in the control group. It was noted that the weight of eggs increased with the age of laying hens. If the average weight of eggs of laying hens of the control group for the period of oviposition $(62.37 \mathrm{~g})$ is taken as $100 \%$, the weight of eggs of hens of the $1 \mathrm{st}$ experimental group was $2.97 \%$, and laying hens of the 2 nd experimental group was $1.12 \%$ more than in the control group. The difference between the 1st and 2nd experimental groups was $1.85 \%$ or $1.15 \mathrm{~g}$. The highest value of the average weight for the experimental period was found in laying hens of all groups aged 54-81 weeks.

Distribution of eggs by categories and output of egg weight. Chicken eggs according to GOST R 52121-2003, depending on their weight, are divided into five categories. Most of the eggs of the highest category were received from laying hens of the first experimental group $-4.05 \%$, which is $1.06 \%$ more than in the control and $0.19 \%$ more than in the second experimental group. The difference between the control and the second experimental group was $0.87 \%$. Most of the eggs of the selected category were also obtained most from laying hens of the first experimental group -
$23.86 \%$, which is $4.71 \%$ more than in the control group and 2.68 $\%$ more than in the second experimental group. The difference between the control and the second experimental group was $2.03 \%$. The analysis of the table shows that the eggs of laying hens of all experimental groups belong mainly to the first category (56.07 $-60.49 \%)$. Most of them were obtained from experimental chickens of the control group- $60.49 \%$, which is more by $4.42 \%$ and $1.91 \%$ than in the first and second experimental groups, respectively. The difference between the first and second experimental groups was $2.51 \%$ (more in the second experimental group). Most eggs of the second category were received from laying hens of the control group - $17.02 \%$, which is $1.27 \%$ more than in the first experimental and $0.92 \%$ more than in the second experimental group. The difference between the first and second experimental groups was insignificant and amounted to $0.35 \%$. Small eggs make up $0.35 \%$ in the control group, which is higher than in the first experimental group by $0.08 \%$.

The egg weight obtained from laying hens during the trial period is an estimated indicator of egg productivity and is calculated by multiplying the number of eggs laid by the hen by their average weight. The highest value of egg mass yield was obtained from laying hens of the first and second experimental groups. In the first experimental group, the egg mass was higher than in the control group by $2.13 \mathrm{~g}$ or $8.8 \%$ and in the second experimental group by $1.28 \mathrm{~g}$ or $5.28 \%$ than in the control group. In the second experimental group, the egg mass was lower by $0.85 \mathrm{~g}$ or $3.51 \%$ than in the first experimental group.

Morphometric parameters of eggs. Egg weight and the ratio of protein, yolk, and shell are important both in incubation and in the production of commercial products and deep processing. It is believed that the weight of eggs is $55 \%$ determined by genetic factors and $45 \%$ depends on feeding and conditions of poultry. The ratio of parts of a chicken egg determines the quality of eggs.

The shape of eggs is one of the main indicators determining their quality. The form of eggs is judged according to their index. Shape index fluctuated in the range of $76.5-79,44 \%$ in the experience conducted by us. With age in the control group, there was a slight decrease in the egg shape index - by $0.3 \%$, after the age of 53 weeks, this figure increased by $0.16 \%$ compared to the first experimental period. In the first and second experimental groups, there was an increase in the form index at the age of 34-53 weeks by $2.14 \%$ and $1.1 \%$, respectively, at the age of 54-81 weeks - a decrease of $0.7 \%$ and $0.52 \%$. The highest form index was in laying hens of the first experimental group at the age of 34-53 weeks, the difference with the control group was $2.94 \%$, with the second experimental group-1.34\%. The difference between the control and the second experimental groups was $1.6 \%$. It should be noted that the increase in the index was observed with the increase in egg weight.

The egg yolk index of the experimental groups of laying hens ranged from 34.5 to $45.38 \%$ and remained virtually unchanged 
during the reproductive period with a tendency to some decrease (table 27). At the beginning of oviposition it was $45.38 \%$ in the control group, which is $3.53 \%$ and $1.58 \%$ more than in the first and second experimental groups, respectively; in the middle- $40.52 \%$ in the control group, which is $1.6 \%$ and $0.72 \%$ more than in the first and second experimental groups, respectively. At the end of the experimental period, it was decreased to $35.8 \%$ in the control group, which is $0.3 \%$ and $1.3 \%$ more than in the first and second experimental groups, respectively.

The protein index decreases slightly with the age of laying hens. This indicator was 7.1\% at 22-33 weeks of the reproductive period in the second experimental group, which is $0.62 \%$ and $1.45 \%$ more than in the control and first experimental groups. The difference between the control and the first experimental groups was $0.83 \%$. At 34-53 weeks in the control group, the protein index was $0.84 \%$ and $0.25 \%$ higher compared to the first and second experimental groups. The difference between the first and second experimental groups was $0.59 \%$ (more in the second experimental group). At the age of 54-81 weeks in the control group, the protein index was 1.19 $\%$ and $0.81 \%$ higher compared to the first and second experimental groups. The difference between the first and second experimental groups was $0.38 \%$ (more in the second experimental group).

Haugh units have the highest relationship with the index concerning the indicators of protein quality. Analyzing the data obtained, we see that during the reproductive period in $22-33 ; 34$ -53 and $54-81$ weeks of age, this figure was at the level of 73.5974.49; 74.97-77.31 and 74.77-75.85 (with an optimal value of 7580). It should be noted that the Haugh unit had the maximum value in laying hens of all experimental groups at the age of 34-53 weeks, with the age of the bird this figure decreased by $0.2 \%$ in the control group, by 1.46 in the first experimental group and by 0.58 in the second experimental group. It should be noted that the indices of protein index and Haugh units are decreasing with the age of laying hens. This may be due to an increase in the residence time of the egg in the laying egg, namely in the uterus, where the formation of the shell and the flow of water into the protein. The optimal ratio of protein and yolk was higher than normal (1.9-2.1) in all eggs of the experimental groups.

Thus, the result of the study of morphometric parameters of eggs obtained from laying hens of the experimental groups showed that enzyme preparations had a positive effect on increasing the weight of eggs and improving their category, increasing the height of the protein, the thickness of the shell, the weight of the protein, yolk and shell, while the best results were obtained from laying hens of the second experimental group-when feeding them amylosubtiline G3x and protosubtiline G3x.

Economic efficiency of the use of enzyme preparations in the diets of laying hens. The lowest feed costs per 10 eggs were in the first experimental group (1.37 kg), which is $90.14 \%$ of the bench- mark. Feed costs amounted to $1.43 \mathrm{~kg}$, which is $94.08 \%$ of the control group in the second experimental group. The difference in feed costs per 10 eggs between the first and second experimental groups was $0.05 \mathrm{~kg}$ or $3.5 \%$. The highest level of profitability of $25.6 \%$ was in the first experimental group, which is $7.4 \%$ more than in the control group and $4.3 \%$ more than in the second experimental group.

\section{Summary}

a. In the scientific and economic experience, the highest rates of egg production were noted in the first experimental group, where laying hens in the composition of complete feed received a mixture of amylosubtilin G3x and cellolux-F - 357.81 eggs, which is $6.48 \%$ higher than in the control group and $1.84 \%$ than in the 2 experimental group. The inclusion in the feed of laying hens of the second experimental group of a mixture of amylosubtilin G3x and protosubtilin G3x contributed to an increase in egg production by $4.64 \%$ than in the control group.

b. The weight of the eggs of the first experimental group was $1.85 \mathrm{~g}$ or $2.97 \%$ more, and the second experimental group was $0.7 \mathrm{~g}$ or $1.12 \%$ more than in the control group. It was noted that the weight of eggs increased with the age of laying hens. The difference between the first and second experimental groups was $1.85 \%$ or $1.15 \mathrm{~g}$.

c. $\quad 1.37-$ of $1.52 \mathrm{~kg}$ of feed was spent in scientific-economic experiment to produce 10 eggs. The lowest feed consumption of $1.37 \mathrm{~kg}$ was in laying hens, in the feed of which a mixture of enzyme preparations amylosubtilin G3x and cellolux F was added, which is less than the control group by $10.94 \%$ and $4.2 \%$ of the second experimental group. The cost of eggs decreased in the first experimental group by 0.33 rubles and in the second experimental group by 0.2 rubles than in the control group. The level of profitability increased by $7.4 \%$ in the first experimental group and by $3.1 \%$ in the second experimental group.

\section{References}

1. Ivanova E Yu, Lavrentev A Yu (2014) Egg production and weight of laying hens' eggs when included in the feed enzyme preparations. Poultry 7: 17-18.

2. Lavrentev A Yu (2016) Domestic enzymes in feed for laying hens: Fundamental and applied aspects of animal feeding and feed technology Materials of the conference dedicated to the $120^{\text {th }}$ anniversary of M F Tomme, Dubrovitsy pp. 134-139.

3. Danilov NV, Lavrentiev A Yu (2017) Dynamics of gain of live weight of young pigs when used as part of feed enzyme preparations of domestic production. Ararian Russia 2: 22-24.

4. Ivanova E Yu, Lavrentev A Yu (2015) The efficiency of inclusion of enzyme preparations in compound feeds for laying hens. Poultry and poultry products $1: 43-45$.

5. Lavrentev A Yu, Ivanova E Yu (2016) Compound feed with domestic enzyme preparations in the feeding of laying hens. Ararian science 1: 20-21. 
6. Lavrentev A Yu (2006) Zeolite-containing Tripoli and IEC. Mixed fodder 7: 66-68.

7. Lavrentev A Yu (2006) Zeolite-containing additive in the diets of pigs. Feed 5: 71-72.

8. Lavrentev A Yu, Smirnov D Yu (2014) Enzymes in feeding young pigs. Agricultural science 8: 26-27.

9. Lavrentev A Yu (2014) L-lysine feed hydrochloride in the composition of the mixture for young pigs. Pig 3: 26-27.
10. Fisinin VI (2009) Poultry in Russia: the strategy of innovative development. M Rosselkhozakademiya pp.147.

11. Smirnov D Yu, Lavrentev A Yu (2013) The use of enzyme preparations in feeding young pigs. Bulletin of the Ulyanovsk State Agricultural Academy 3(23): 109-113.

12. Smirnov D Yu, Lavrentev A Yu (2013) The combined use of enzyme preparations and their effect on meat productivity. Pig 8: 33-35. 